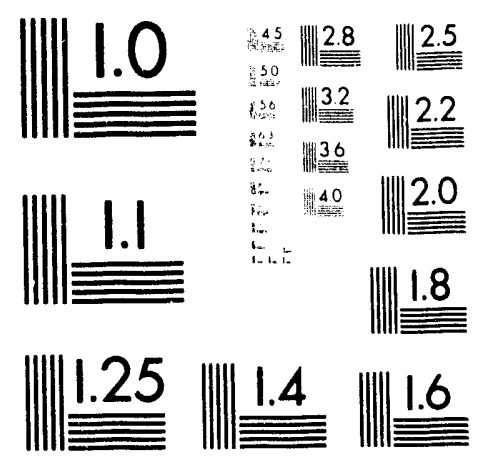



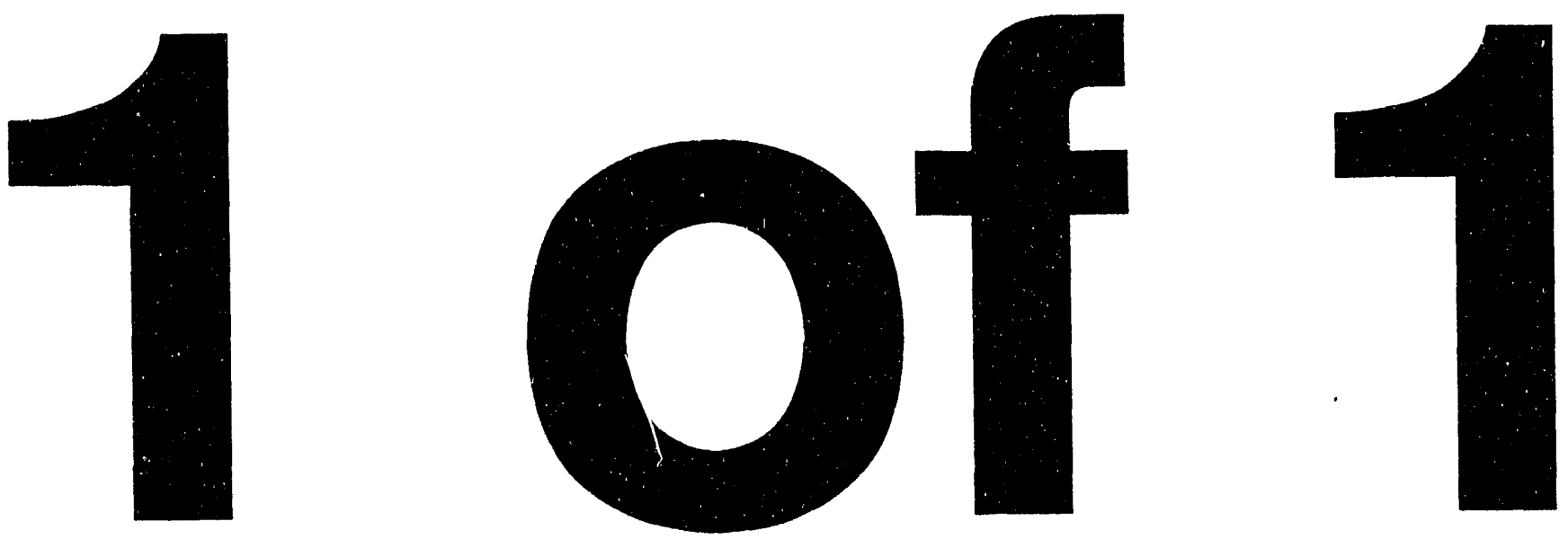


\title{
Design Considerations for High-Current Superconducting Ion Linacs
}

\author{
J. R. Delayen, C.L. Bohn, B.J. Micklich, C.T. Roche, and L. Sagalovsky \\ Argonne National Laboratory, Engineering Physics Division \\ 9700 South Cass Avenue, Argonne, Illinois 60439
}

\begin{abstract}
Superconducting linacs may be a viable option for highcurrent applications such as fusion materials irradiation testing, spallation neutron source, transmutation of radioactive waste, tritium production, and energy production. These linacs must run reliably for many years and allow easy routine maintenance. Superconducting cavities operate efficiently with high $\mathrm{cw}$ gradients, properties which help to reduce operating and capital costs, respectively. However, cost-effectiveness is not the sole consideration in these applications. For example, beam impingement must be essentially eliminated to prevent unsafe radioactivation of the accelerating structures, and thus large apertures are needed through which to pass the beam. Because of their high efficiency, superconducting cavities can be designed with very large bore apertures, thereby reducing the effect of beam impingement. Key aspects of high-current cw superconducting linac designs are explored in this context.
\end{abstract}

\section{INTRODUCTION}

Questions regarding the design of linear accelerators with high duty factor for the long-term production of high-current ion beams center as much on beam physics as on hardware. The pervasive concern is whether dynamical phenomena which generate a diffuse halo of beam particles can be sufficiently controlled to limit radioactivation induced by beam impingement to safe levels.' For example, as indicated in Section II below, the maximum tolerable amount of beam impingement is of the order of $0.03 \mathrm{nA} / \mathrm{m}$ for $1 \mathrm{GeV}$ protons. The heat load associated with this level of impingement is $30 \mathrm{~mW} / \mathrm{m}$. The if losses on a superconducting cavity will be $\sim 20-40$ $\mathrm{W} / \mathrm{m}$, and therefore radioactivation is by far the dominant concern related to beam impingement on superconducting structures. This concern is equally important for copper accelerators. Because shunt impedance is of less concern in superconducting cavities, they can be designed to operate at low frequency and with large bore-hole apertures to mitigate impingement. This constitutes additional degrees of freedom which are available in the design of high-current linacs. In Section III bolow, we provide four generic superconducting cavity geometries designed specifically for use in these highcurrent linacs.

\section{L!MITS ON PERMISSIBLE RADIOACTIVATION}

For a low-energy (35-40 MeV) deuteron accelerator, such as that being proposed for a $\mathrm{d}+\mathrm{Li}$ neutron source for fusion materials testing, the most important reactions are the $(d, p)$

Work supported by the U.S. Department of Energy under contract W-31-109-ENG-38 and by the Strategic Defense Initiative Organization. and $(d, 2 n)$ reactions, with $(d, n),(d, \alpha)$, and other reactions being somewhat less important. The neutrons produced through $(d, x n)$ reactions can also produce activation. Experiments have shown that neutron yield is higher in copper than in niobium by a factor of about two at $E_{d}=10-15 \mathrm{MeV}$, and we use that assumption up through $40 \mathrm{MeV}$. This is consistent with the variations in $(n, 2 n)$ cross sections such as shown by Barbier. ${ }^{2}$

Radionuclides produced from niobium have either very short or very long half-lives. Thus, the dose rate beginning a few hours after shutdown should be smaller relative to that from copper. For niobium, the dominant dose from direct $D$ activation is due to ${ }^{93} \mathrm{Mo}^{\mathrm{w}}(6.9 \mathrm{~h})$. The neutron-induced activity in niobium is predominantly due to ${ }^{9} \mathrm{Nb}^{\mathrm{m}}(10.13 \mathrm{~d})$.

For copper, ${ }^{63} \mathrm{Zn}(38.3 \mathrm{~m})$ and ${ }^{62} \mathrm{Cu}(9.8 \mathrm{~m})$ cominate the dose rate at short times following irradiation. Of particular interest is ${ }^{65} \mathrm{Zn}$ (243.8 days), since this nuclide builds up over long irradiations and thus dominates the dose rate after several days for irradiation times of around 300 days. Other $(d, p)$ and $(d, 2 n)$ activities in $\mathrm{Cu}$ decay rapidly. At longer times following shutdown, ${ }^{64} \mathrm{Cu}(12.8 \mathrm{~h}$ ) can also be important, as well as ${ }^{60} \mathrm{Co}(5.27 \mathrm{y})$ from ${ }^{63} \mathrm{Cu}(\mathrm{n}, \alpha)$ for long irradiation times.

Table 1. Dose rates in $\mathrm{mrem} / \mathrm{h}$ at $30 \mathrm{~cm}$ distance from copper and niobium $35-\mathrm{MeV} \mathrm{D}$ accelerators for $1 \mathrm{nA} / \mathrm{m}$ current loss and 1 to $5 \mathrm{~N} / \mathrm{V} / \mathrm{m}$ average gradient.

\begin{tabular}{lllll}
\hline $\mathrm{t}_{\mathrm{ab}}$ & $\begin{array}{c}\mathrm{Cu} \\
\mathrm{t}_{\mathrm{irr}}=30 \text { days }\end{array}$ & $\begin{array}{c}\mathrm{Nu} \\
\mathrm{t}_{\mathrm{irr}}=300 \text { days }\end{array}$ & $\begin{array}{c}\mathrm{Nb} \\
\text { days }\end{array}$ \\
\hline $0 \mathrm{~h}$ & 21. & 4.4 & 23. & 4.4 \\
$1 \mathrm{~h}$ & 5.7 & 4.2 & 7.4 & 4.2 \\
$8 \mathrm{~h}$ & 2.0 & 3.1 & 3.8 & 3.1 \\
$24 \mathrm{~h}$ & 1.0 & 2.2 & 2.7 & 2.2 \\
$30 \mathrm{~d}$ & 0.43 & 0.31 & 2.1 & 0.31
\end{tabular}

Accelerator activation was estimated for a constant 1 $\mathrm{nA} / \mathrm{m}$ current loss and an average gradient of $1 \mathrm{MV} / \mathrm{m}$, with the results shown in Table 1 . For 30 days irradiation time $\left(t_{i r}\right)$, the copper dose is much higher for short time after shutdown $\left(t_{\mathrm{sh}}\right)$. The dose for niobium is higher from a few hours to a few days following shutdown (due to ${ }^{2} \mathrm{Nb}^{\mathrm{m}}$ ), while the copper is again higher at 30 days, although the difference is small. For an irradiation time of 300 days, the dose in copper is higher at all times following shutdown because of the ingrowth of ${ }^{65} \mathrm{Zn}$. Dose rates are relatively insensitive to gradient, decreasing somewhat at higher gradient, assuming a constant deuteron loss per unit length; however, the amount of irradiated anaterial will be greater for a lower gradient (longer accelerator).

For high-energy proton accelerators, neutron yields increase with higher $\mathrm{Z}$ for proton bombardment. The range

PISTRIBUTIBN OF THIS DOCUMENT IS UNIIMITES 
of $1 \mathrm{GeV}$ protons in both niobium and copper is of order 40 $\mathrm{cm}^{3}$ and because the wall thickness of the cavities is much less than the range, radioactivation of niobium should be slightly more, but comparable to, that of copper. Thus, for a proton beam, the current loss in both niobium and copper needs to be less than $0.2 \mathrm{nA} / \mathrm{m}$ at $200 \mathrm{MeV}$, and less than $0.03 \mathrm{nA} / \mathrm{m}$ at $1 \mathrm{GeV}$, to be under $2.5 \mathrm{mrem} / \mathrm{hr}$ at a distance of $1 \mathrm{~m}$ from the linac one hour after shutdown. ${ }^{4}$

\section{LARGE-BORE SUPERCONDUCTING CAVITIES}

\section{General considerations}

Geometries of low-velocity superconducting resonators generally incorporate an inner conductor which provides a TEM-like accelerating mode. ${ }^{s}$ The center-gap to center-gap distance in these structures is of order $B \lambda / 2$, where $B=v / c$ is the beam velocity, and $\lambda$ is the rf wavelength. For velocities less than $\sim 0.1 \mathrm{c}$ and frequencies of several hundred $\mathrm{MHz}$, this distance becomes too small for practical resonators, and this consideration is a principal motivator for superconducting RFQs which provide proton energies to $\sim 8 \mathrm{MeV}^{6}$ For proton energies ranging from $8 \mathrm{MeV}$ to $2 \mathrm{GeV}$, the corresf onding velocity range is $B=0.1-0.9$. Superconducting resonators have recently been developed for frequencies in the range $350-850 \mathrm{MHz}$ and optimized for velocities up to $B=0.3$. Off-line experiments with these structures have yielded high accelerating gradients. ${ }^{7,8}$ Of these structures, the easiest to fabricate is the spoke resonator shown in Fig. 1. This geometry is also modular, for several units can be stacked together to make a multigap cavity. For these reasons, we use the spoke as the baseline geometry for superconducting cavities to be used in high-current linacs.

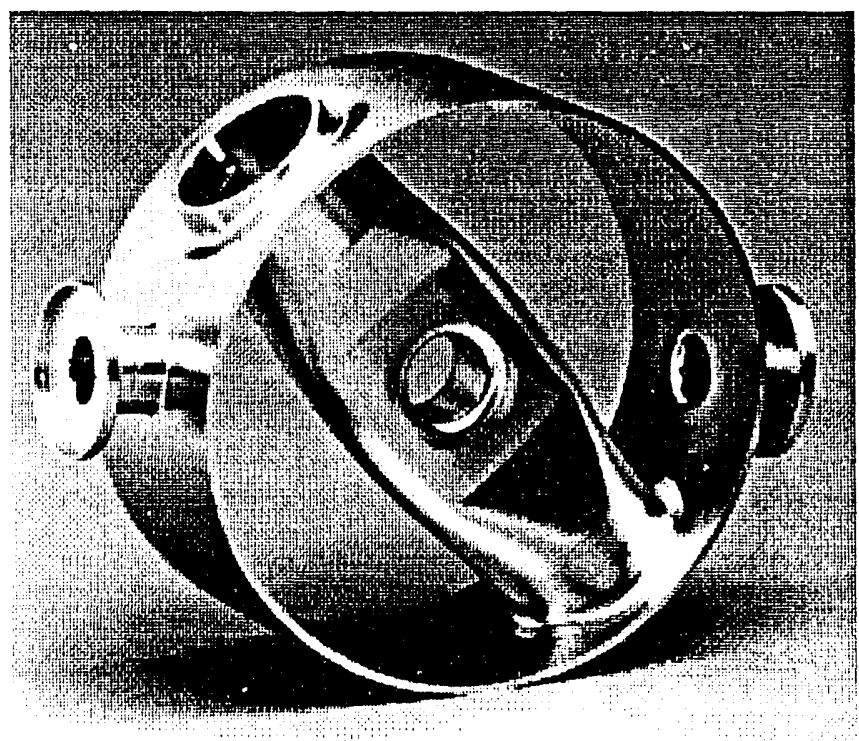

Figure 1. $850 \mathrm{Mhz}, \beta=0.28,2$-gap spoke resonator prior to the welding of the end plates.

The choice of frequency hinges on a number of considerations. One of them is the ability to provide large-bore apertures for the beam, and this favors lower frequencies and larger cavities. Large bores also provide lower transverse shunt impedances which reduce cumulative beam breakup. The availability of $\mathrm{rf}$ power is a second concern.

On the other hand, it has been inferred from numerical simulations that high frequencies mitigate enittance growth by lowering the charge per bunch. ${ }^{9}$ This is a major consideration when emittance preservation is crucial. For most of the highcurrent applications, however, emittance growth is a concern only in connection with halo formation and beam transport. A detailed understanding of the effects of bunching on highcurrent beams is a fundamental building block for the design of these linacs, and this will be the topic of future investigations.

One possible strategy for achieving high currents is to combine two beams by funneling them together at a relatively low energy, a process which doubles the if frequency. To achieve large bores and use a common frequency for if power amplifiers, we shall assume the linac operates at $350 \mathrm{MHz}$, and that prior to funneling, the frequency is $175 \mathrm{MHz}$.

\section{Cavity geometries}

As shown in the examples of Figs. 2 and 3, the spoke geometry can be adapted to span a wide velocity range. For high velocities it becomes more practical to introduce singlecell structures like that shown in Fig. 4, or multicell structures like that shown in Fig. 5. The properties of these large-bore geometries, which were calculated with MAFIA in the case of the spoke resonators and SUPERFISH in the case of the "elliptical" cavities, are given in Table 2 below. In the Table, resonators $\# 1-\# 4$ refer to the $175 \mathrm{MHz}, B=0.125$ spoke, the $350 \mathrm{MHz}, B=0.45$ spoke, the $350 \mathrm{MHz}, B=0.45$ single-cell, and the $350 \mathrm{MHz}, B=0.8$ two-cell, respectively.

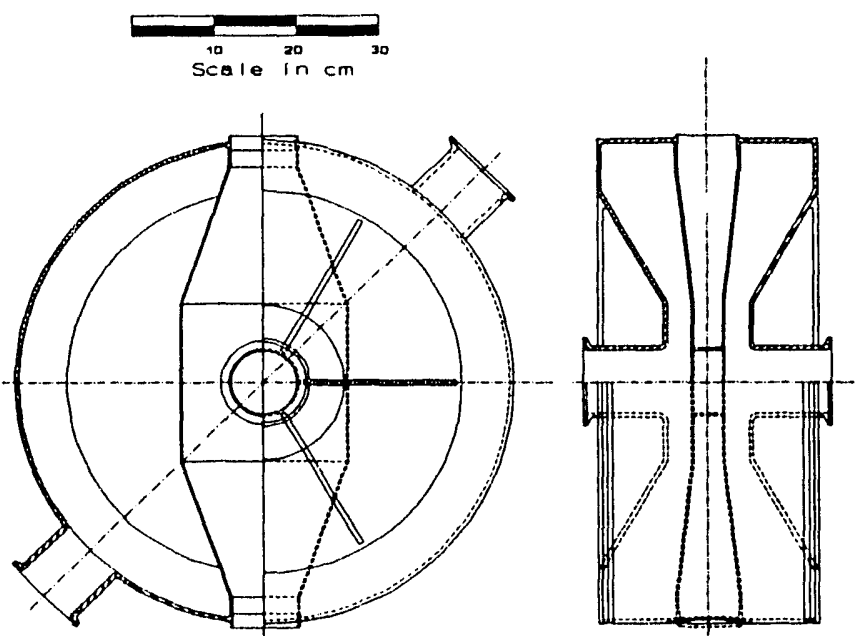

Figure 2. $175 \mathrm{MHz}, \beta=0.125$, 2-gap spoke resonator.

Compared to two-gap spoke resonators, two-cell "elliptical" cavities generally have higher shunt impedances and lower rf surface fields. They are also comparatively simple and easy to fabricate. However, for a given frequency, these structures are also much larger than the spoke, and are likely to be less mechanically rigid. 
Table 2. Comparison of resonator properties.

\begin{tabular}{lllll}
\hline & $\# 1$ & $\# 2$ & $\# 3$ & $\# 4$ \\
\hline $\mathrm{B}_{\mathrm{p}} / \mathrm{E}_{\mathrm{acc}}[\mathrm{G} /(\mathrm{MV} / \mathrm{m})]$ & 122 & 125 & 41.6 & 35.9 \\
$\mathrm{R}_{\mathrm{ab}}\left(10^{5} \mathrm{M} \Omega\right)$ & 1.3 & 1.5 & 1.2 & 6.7 \\
$\mathrm{R}_{\mathrm{ab}} / \mathrm{Q}(\Omega)$ & 47.1 & 121 & 51.3 & 205 \\
$\mathrm{P}(\mathrm{W})^{-}$ & 2.73 & 9.65 & 9.0 & 14.5 \\
$\Delta V(\mathrm{MV})^{\dagger}$ & 0.6 & 1.2 & 1.0 & 3.1 \\
Diameter (cm) & 60 & 38 & 74 & 76
\end{tabular}

Assumes BCS R, at T $=4.2 \mathrm{~K},{ }^{\dagger}$ At $\mathrm{E}_{2 x}=6 \mathrm{MV} / \mathrm{m}$.
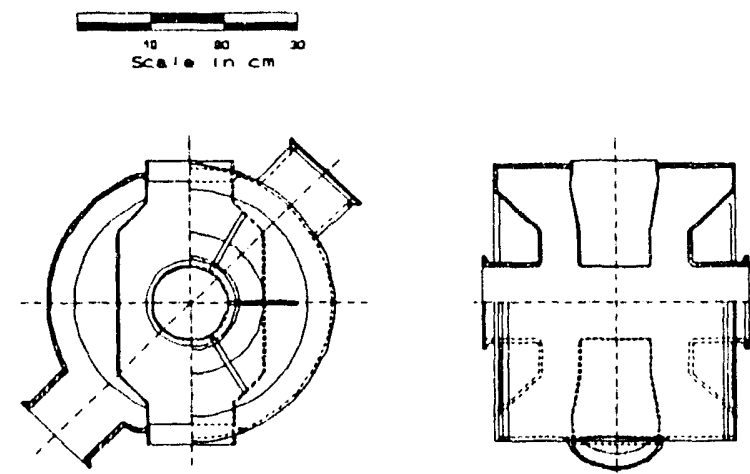

Figure 3. $350 \mathrm{MHz}, \beta=0.45,2$-gap spoke resonator.

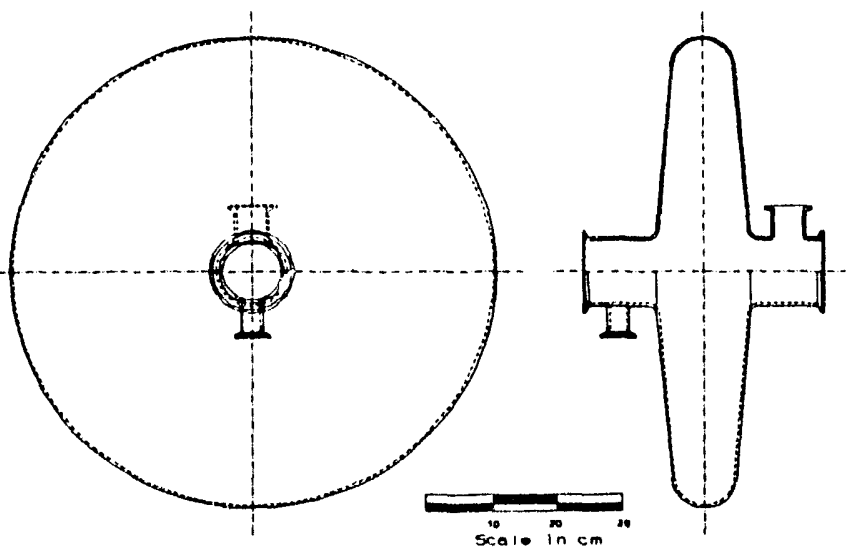

Figure 4. $350 \mathrm{MHz}, \beta=0.45$, Single-cell $\mathrm{TM}_{010}$ resonator.
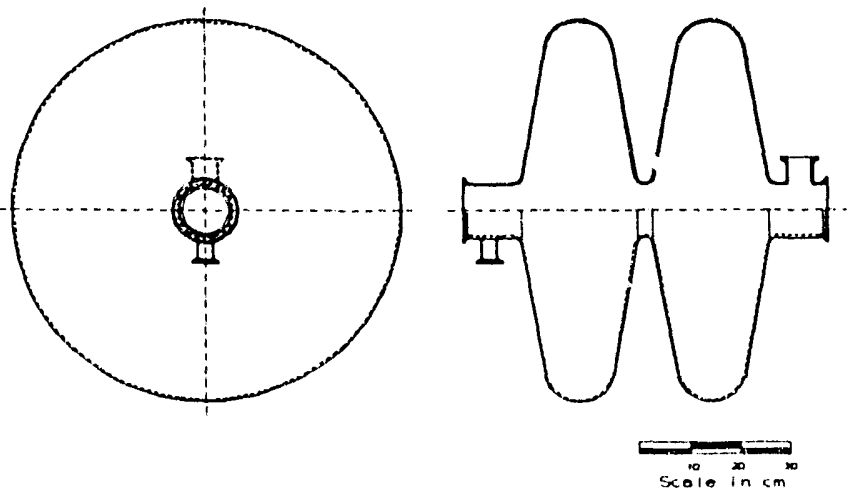

Figure 5. $350 \mathrm{MHz}, \beta=0.8,2$-cell $\mathrm{TM}_{010}$ resonator.
It remains to be determined where to transition from the spoke geometry to multicell structures in a full linac design. It is also of interest to determine the optimum number of gaps or cells for each structure. Beam dynamics and the availability of $\mathrm{rf}$ power influence this question. The required lattice period of focusing elements will be shorter at lower velocities. A requirement that the linac be operable when one or more structures have failed will place an additional constraint on structure length. The amount of $\mathrm{rf}$ power which may be input to the cavity will be limited by the capability of the coupler, and this places the most stringent restriction on structure length in high-current linacs.

\section{CONCLUSIONS}

Radiofrequency superconductivity offers a number of advantages for high-current, high-duty-factor linacs, among these is the ability to open up the cavity apertures to mitigate beam impingement and its associated radioactivation. The cavities also may be expected to operate at a higher real-estate gradient than their normal-conducting counterparts. There are no known show-stoppers for if superconductivity in these applications; the associated beam physics is beginning to be understood, appropriate accelerating structures have been designed

An important uncertainty in the design of these linacs is the projected capability of $\mathrm{rt}^{\prime}$ power couplers. Coupler development and continued beam-physics research are key components of the development path. A more important and fundamental component, however, is a high-current ion-beam test of superconducting structures. ${ }^{7}$

\section{REFERENCES}

[1] C.L. Bohn and J.R. Delayen, "Halo Formation in Mismatched, Space-Charge-Dominated Beams", these Proceedings.

[2] M. Barbier, Induced Radioactivity, North Holland (1969). [3] D.H. Perkins, Introduction to High-Energy Physics, (Addison-Wesley, Reading, MA, 1972), p. 29.

[4] N.I. Golubeva, et al. "Problems of Beam Loss in Intense Ion Linear Accelerators", Proceedings of the 1988 Linear Accelerator Conference, p. 669 (1988).

[5] J.R. Delayen, C.L. Bohn, and C.T. Roche, "Niobium Resonator Development for High-Brightness Ion Beam Acceleration", IEEE MAG-27, pp. 1924-1927, (1991).

[6] J.R. Delayen, C.L. Bohn, W.L. Kennedy, L.Sagalovsky, "Design Considerations for High-Current Superconducting RFQ", these Proceedings.

[7] J.R. Delayen, et al. "Recent Developments in the Application of RF Superconductivity to High-Brightness and High-Gradient Ion Beam Accelerators", Proc. 5th Workshop on RF Superconductivity, DESY Report No. M-92-01,

[8] J.R. Delayen, W.L. Kennedy, and C.T. Roche, "Design and Test of a Superconducting Structure for High-Velocity Ions", Proc. 1992 Linear Accelerator Conference, AECL Report No. 10728, pp. 695-697 (1992).

[9] T.P. Wangler, "High-Brightness Injectors for Hadron Colliders", in Frontiers of Particle Beams: Intensity Limitations, (Springer-Verlag, Berlin, 1992), pp. 542-561. 


\section{DISCLAIMER}

This report was prepared as an account of work sponsored by an agency of the United States Government. Neither the United States Government nor any agency thereof, nor any of their employees, makes any warranty, express or implied, or assumes any legal liability or responsibility for the accuracy, completeness, or usefulness of any information, apparatus, product, or process disclosed, or represents that its use would not infringe privately owned rights. Reference herein to any specific commercial product, process, or service by trade name, trademark, manufacturer, or otherwise does not necessarily constitute or imply its endorsement, recommendation, or favoring by the United States Government or any agency thereof. The views and opinions of authors expressed herein do not necessarily state or reflect those of the United States Gcvernment or any agency thereof. 

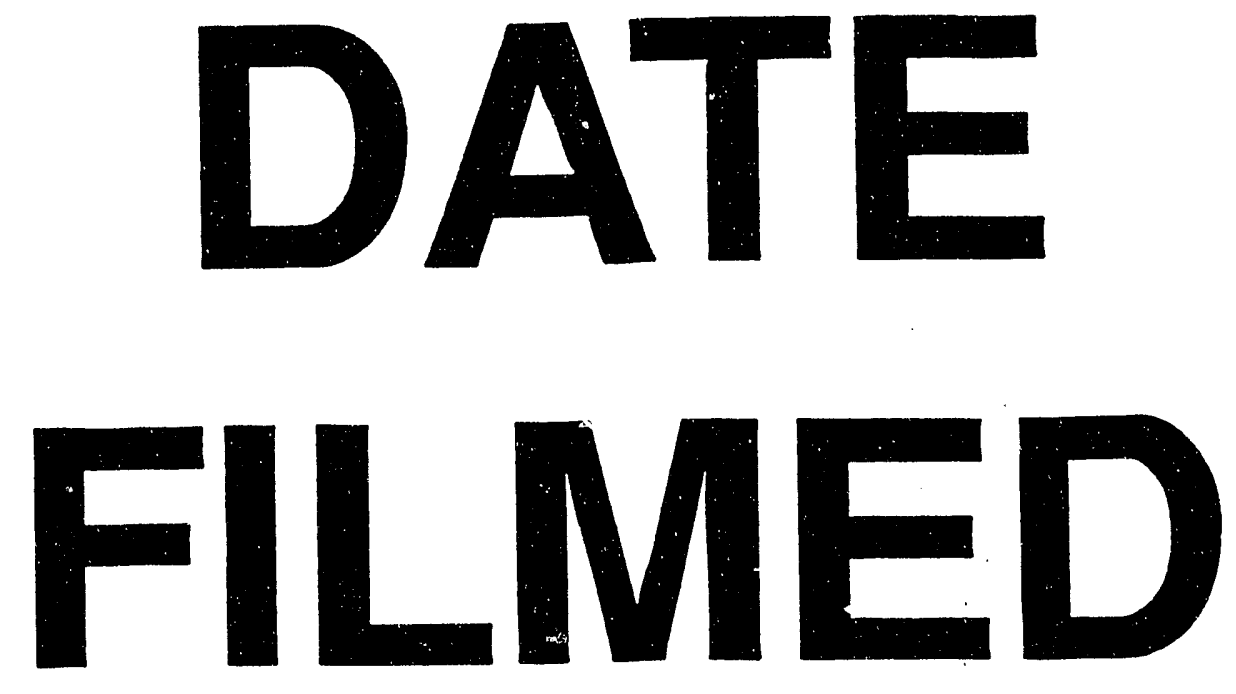

$10 / 13 / 93$
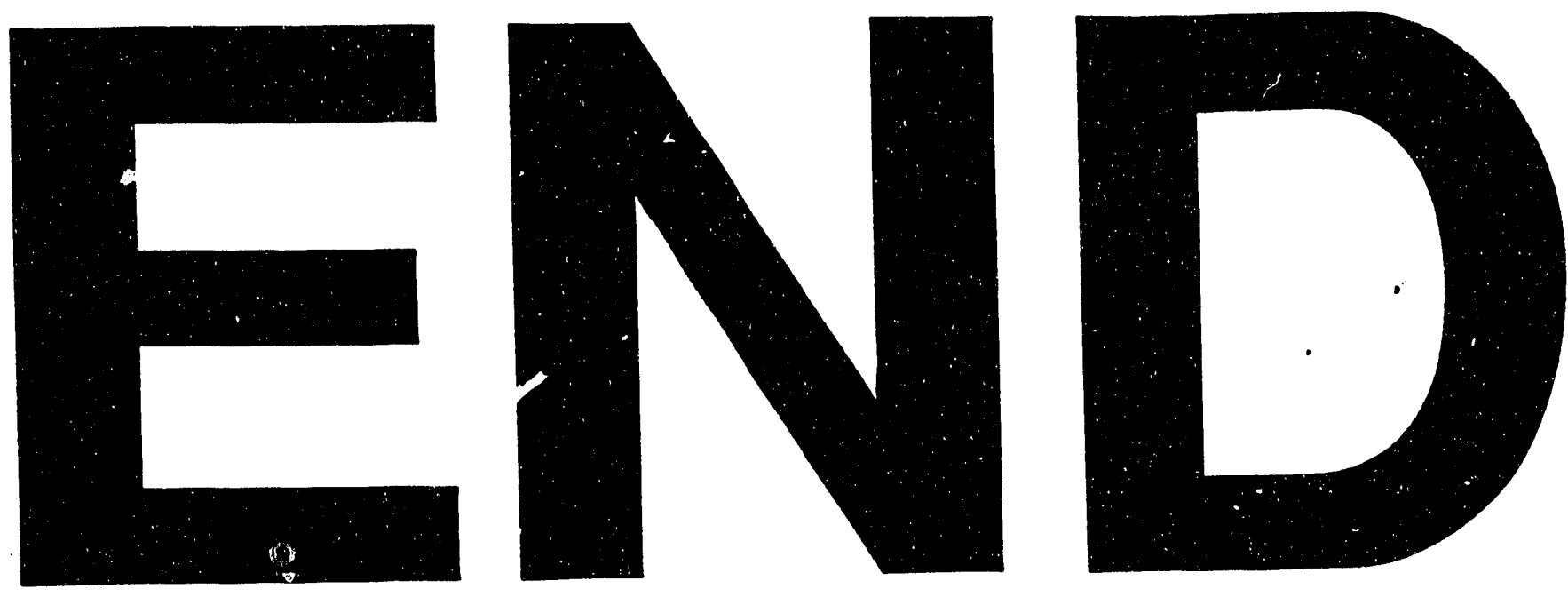


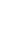

